\title{
Evidence for Selective Accumulation of Intrathyroidal T Lymphocytes in Human Autoimmune Thyroid Disease Based on T Cell Receptor V Gene Usage
}

\author{
T. F. Davies, A. Martin, E. S. Concepcion, P. Graves, N. Lahat, ${ }^{\star}$ W. L. Cohen, ${ }^{\star}$ and A. Ben-Nun ${ }^{\star}$ \\ Department of Medicine, Mount Sinai School of Medicine, New York 10029; *Clinical Immunology Division, Lady Davis Carmel \\ Hospital, Haifa, Israel; and ${ }^{\ddagger}$ Department of Cell Biology, Weizmann Institute of Science, Rehovot, Israel
}

\begin{abstract}
We have investigated the $T$ cell receptor $V \alpha$ and $V \beta$ gene family usage by $T$ lymphocytes infiltrating affected thyroids in patients with autoimmune thyroid disease. We show that the intrathyroidal T lymphocytes from patients $(n=6)$ with autoimmune thyroid disease display a widespread usage of $\mathrm{V} \beta$ gene families with an average of $14.4 / 19 \mathrm{~V} \beta$ gene families similar to the peripheral $\mathrm{T}$ lymphocytes of the same patients. Because we recently reported that the utilization of $\mathrm{V} \alpha$ gene families is markedly reduced within these mitogen-stimulated intrathyroidal $T$ cell populations, as well as within intact tissue from similar patients $(n=4)$ (overall mean of $4.0 / 18$ families detected), these results indicate that in thyroids of patients with autoimmune thyroid disease the lymphocytes are selectively accumulating based on their $V \alpha$ rather than $V \beta$ elements. This preferential hTcR $V \alpha$ and widespread $V \beta$ gene usage was not mimicked in most 7-d autologous mixed lymphocyte reactions using non-T cell stimulators $(n=6)$ or EB-virus immortalized autologous $B$ cell lines $(n=3)$. Hence, the selective $V$ gene utilization by intrathyroidal $\mathbf{T}$ cells is likely to be secondary to multiepitopic thyroidal autoantigens activating thyroid infiltrating $T$ cells or to the presence of a superantigenlike thyroidal self-antigen, capable of determining a selective infiltration or activation of a variety of $\mathrm{T}$ lymphocytes on the basis of their $\mathrm{V} \alpha$ gene usage. (J. Clin. Invest. 1992. 89:157-162.) Key words: human autoimmune thyroid disease $\cdot \mathrm{T}$ cell receptor $\cdot \mathrm{V}$ gene
\end{abstract}

\section{Introduction}

In examination of the intrathyroidal environment of autoimmune thyroid disease we have demonstrated specific accumulation of $T$ cell subsets (1). Furthermore, in animal models, CD4+ T lymphocytes, reactive against specific thyroidal protein (thyroglobulin), are able to transfer disease indicating their role in the pathogenesis of thyroiditis $(2,3)$. A similar situation has been observed in experimental autoimmune encephalitis and human multiple sclerosis with $\mathrm{T}$ cells specifically reactive to myelin basic protein $(4,5)$. Studies of functional murine and rat $\mathrm{T}$ cell receptor $(\mathrm{TcR})^{1} \mathrm{~V}$ genes, which encoded $\mathrm{T}$ cells capa-

Address correspondence to Dr. T. F. Davies, Box 1055, Mount Sinai Medical Center, 1 Gustave L. Levy Place, New York, NY 10029.

Received for publication 06 June 1991 and in revised form 04 September 1991.

1. Abbreviations used in this paper: AMLR, autogous mixed lymphocyte reaction; PBMC, peripheral blood mononuclear cell; PCR, polymerase chain reaction; $\mathrm{TcR}, \mathrm{T}$ cell receptor.

J. Clin. Invest.

(C) The American Society for Clinical Investigation, Inc.

$0021-9738 / 92 / 01 / 0157 / 06 \$ 2.00$

Volume 89, January 1992, 157-162 ble of transferring encephalitis, were found to be highly restricted in their usage of both TcR $\alpha$ and $\beta$ gene families (6) and similar findings have been reported in human $T$ cells both in situ and reactive to myelin basic protein $(7,8)$. We have recently observed restricted usage of $h T c R$ V $\alpha$ genes in the T cells of the inflammatory infiltrate rescued from thyroid tissue in patients with autoimmune thyroid disease (9). These data raised the obvious question of whether such thyroid infiltrating $\mathrm{T}$ cells also demonstrated a similar hTcR V $\beta$ gene restriction.

Here we report that these thyroid infiltrating $T$ lymphocytes display a widespread usage of $h T c R ~ V \beta$ gene families indicating a selective infiltration or accumulation of the intrathyroidal $\mathrm{T}$ lymphocytes based on their $\mathrm{V} \alpha$ elements. Because the proportion of thyroid-infiltrating $T$ cells which are antigen-specific appears to be small (10-12), we examined the possibility that their preferential accumulation in the thyroid is related to either their reactivity against self HLA class II antigen (an "in vivo mixed lymphocyte reaction") in the thyroid (13-15) or against a superantigen-like thyroidal antigen, activating the infiltrating $T$ lymphocytes on the basis of their $h T c R$ $\mathrm{V} \alpha$ gene usage.

\section{Methods}

Patients and surgical material. Euthyroid patients undergoing surgery for autoimmune thyroid disease (Graves' disease, $n=6$; autoimmune [Hashimoto's] thyroiditis, $n=4$ ) or removal of single or multiple thyroid adenomas $(n=7)$ and one papillary thyroid carcinoma, were chosen without selection and on the basis of specimen availability. Peripheral blood mononuclear cells alone were also available from a further six patients with autoimmune thyroid disease (Graves' disease, $n=2$; autoimmune thyroiditis, $n=4)$. Normal controls $(n=4)$ were unselected laboratory personnel. Autoimmune thyroid disease was as defined previously (9). All patients with Graves' disease were treated with antithyroid drugs (methimazole or propylthiouracil) at the time of sampling. Surgical patients with Graves' disease had received 2 wk of iodine supplements before surgery. Surgical tissue was obtained within $30 \mathrm{~min}$ of removal and utilized immediately on receipt.

$T$ cell preparations. Peripheral blood mononuclear cells (PBMC) were prepared from heparinized blood by density gradient centrifugation using Ficoll-Hypaque (Pharmacia Fine Chemicals, Piscataway, $\mathrm{NJ}$ ) and stored in liquid nitrogen. Intrathyroidal lymphocytes were obtained by collagenase digestion of the surgical thyroid tissue followed by density gradient centrifugation as previously $(1,9)$ and stored frozen in liquid nitrogen. Between 2 and $5 \times 10^{6}$ cells were obtained per sample. All lymphocytes, unless stated otherwise, were subsequently thawed (with $80-90 \%$ viability as evidenced by Trypan Blue staining) and expanded in Hepes-buffered RPMI-1640 medium containing penicillin and streptomycin (Gibco, Grand Island, NY) with 10\% FBS, $10 \%$ interleukin-2 (Biotest Inc., Frankfurt, FRG) and, unless stated otherwise, $1 \mu \mathrm{g} / \mathrm{ml}$ phytohemagglutinin (PHA) (Sigma Chemical Co., St. Louis, MO) for 5-6 d. We have previously determined that such mitogenic treatment does not significantly influence the pattern of $V$ gene expression (9).

Autologous MLRs. Classical AMLRs were performed as previously 
described (16). Briefly, $T$ cells and non-T cells were separated from PBMC by AET-rosetting and non-T cells were inhibited using mitomycin C (100 $\mu \mathrm{g} / \mathrm{ml})$ for $1 \mathrm{~h}$. AMLRs were performed using $2 \times 10^{5}$ cells/200 $\mu$ l RPMI-1640/5\% FCS at a 1:1 ratio. After $5 d$ incubation, cultures were supplemented with $1 \mu \mathrm{Ci}$ of $\left[{ }^{3} \mathrm{H}\right]$-thymidine (New England Nuclear, Boston, MA; $0.5 \mu \mathrm{Ci} /$ well) and harvested $24 \mathrm{~h}$ later. Autologous mixed lymphocyte reactions were also performed using lymphoblastoid cell lines as stimulators. Briefly, $10^{5}$ patient or control PBMC were incubated with $10^{4} 100 \mathrm{~Gy}$ gamma-irradiated autologous Epstein-Barr virus transformed lymphoblastoid cell lines (EB virus was a kind gift of Dr. N. H. Sigal, Merck Sharp and Dohme Research Laboratories, Rahway, NJ) in 10\% FBS/90\% RPMI 1640 (with Hepes buffer and L-glutamine) supplemented with $1 \%$ penicillin/streptomycin (Gibco) in $0.2 \mathrm{ml}$ vol for $\mathbf{7} \mathrm{d}$ in two sets of quadruplicates and fed every 3-4 d. PBMC alone or irradiated lymphoblastoid cells alone served as controls. One set of quadruplicates was labeled for the last 18 $\mathrm{h}$ with $\left[{ }^{3} \mathrm{H}\right]$-thymidine, harvested, and counted. The second set of quadruplicates was pooled and simultaneously processed for RNA extraction.

$h T c R$ polymerase chain reactions (PCR). Total cellular RNA was extracted from PBMC, the T cell cultures and intact surgical thyroid specimens using guanidinium thiocyanate and phenol (RNAzol B; Cinna/Bioteck Laboratories International Inc., Friendswood, TX) and stored in alcohol/saline. Complementary DNA (cDNA) transcripts were prepared using oligo- $d T$ priming and avian reverse transcriptase (Life Sciences Inc., St. Petersburg, FL) as described elsewhere $(8,9)$ and the cDNA, synthesized from the equivalent of $10 \mu \mathrm{g}$ total cellular RNA for all specimens, was stored in $200 \mu \mathrm{l}$ sterile water. For the amplification of the hTcR mRNA transcripts we synthesized 18 different $\mathrm{V} \alpha$ gene (9) and $19 \mathrm{~V} \beta$ (17) oligonucleotide $5^{\prime}$ amplimers using a DNA synthesizer (Applied Biosystems Inc., Culver City, CA) and paired them with a $3^{\prime}$ primer matched to $\mathrm{C} \alpha$ or $\mathrm{C} \beta 1$ constant region genes (Fig. 1). The oligonucleotides were initially assessed for purity by PAGE and subsequently used without further purification. The predicted size of the amplified PCR fragments based on the individual V gene families was subsequently utilized in the recognition of $\mathrm{V}$ gene family specific bands. For the PCR reactions, $5 \mu 1$ of denatured cDNA was amplified in a $25-\mu \mathrm{l}$ final vol with $1 \mathrm{U}$ Taq DNA polymerase, $0.3 \mu \mathrm{g}$ of both primers, Taq polymerase buffer and with $1.5 \mathrm{mM}$ of each dNTP. We carried out 35 cycles of amplification by using a step program $\left(95^{\circ} \mathrm{C}, 1\right.$ min, $56^{\circ} \mathrm{C}, 2 \mathrm{~min}$, and $72^{\circ} \mathrm{C}, 3 \mathrm{~min}$ ) followed by a 10 -min extension at $72^{\circ} \mathrm{C}$ (model PTC100 Programmable Thermal Controller; M. J. Research Inc., Cambridge, MA). Negative controls included tubes without cDNA. The amplified products were subjected to electrophoresis on $1.5 \%$ agarose gels with ethidium bromide and visualized under UV light using a 123-bp molecular size control ladder (BRL Inc., Gaithersburg, MD).

$h T c R V$ gene hybridization. To improve the sensitivity of fragment detection and to examine the specificity of the PCR products the agarose gels were transblotted onto nitrocellulose membranes (Hybond-C; Amersham Corp., Arlington Heights, IL), baked, and prehybridized as described $(8,9)$. All blots were subsequently hybridized with a ${ }^{32} \mathrm{P}$ gamma ATP-labeled oligonucleotide probe specific to the $\mathrm{C} \alpha$ or $\mathrm{C} \beta-1$ regions and internal to the predicted hTcR products (Fig. 1). Approximately $5 \times 10^{5} \mathrm{cpm} / \mathrm{ml}$ of probe was hybridized with each filter for $18 \mathrm{~h}$

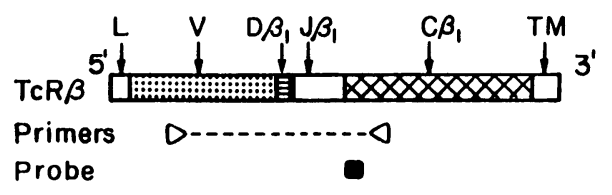

Figure 1. Diagrammatic representation of $\mathrm{hTcR} V \beta$ oligonucleotides utilized (17). We also used similar TcR V $\alpha$ oligonucleotides as described previously (9). The probes employed were C $\alpha$ 5'-GTACACGGCAGGGTCAGGGTTCTGGAT-3' and C $\beta$ 5'-TTCTGATGGCTCAAACACAGCGACCTCGGG-3'. at $42^{\circ} \mathrm{C}$ in $6 \times \mathrm{SSC}, 1 \times$ Denhart's solution, $0.05 \%$ sodium pyrophosphate, and tRNA. The filters were washed in $2 \times$ SSC with $0.05 \%$ sodium pyrophosphate at increasing temperatures $\left(50^{\circ} \mathrm{C}, 60^{\circ} \mathrm{C}\right.$, and $70^{\circ} \mathrm{C}$ ). After each washing the blots were exposed to $\mathrm{x}$-ray film with an intensifying screen at $-80^{\circ} \mathrm{C}$ for $3-24 \mathrm{~h}$.

Quantitative $h T c R V$ gene assessments and statistical analyses. To derive quantitative data on the proportion of $h T c R$ V gene utilization the autoradiographs were examined by computerized quantitative densitometry in a model 300A densitometer (Molecular Dynamics Inc., Sunnyvale, CA) using a mathematical procedure for the derivation of area volume from autoradiographic scanning (Image Quant Version 2.0). Only PCR products conforming to the predicted sizes of the appropriate $\mathrm{V}$ genes were counted (9). Each $\mathrm{hTcR} V$ gene was then expressed as a percentage of the total of $\mathrm{V} \alpha$ or $\mathrm{V} \beta$ genes detected as evidenced by that particular scan. Data were compared using Student's $t$ test where appropriate.

\section{Results}

$h T c R V \alpha$ and $V \beta$ gene amplification in PBMC. We have previously reported $\mathrm{V} \alpha$ gene family utilization in normal PBMC and found a mean \pm SEM of $17.3 \pm 0.3$ of the 18 gene families utilized (9). PBMC from patients with autoimmune thyroid disease provided similar data. In a more limited control study for the present experiments we found 17.6 $\pm 0.8(n=3) \mathrm{V} \alpha$ genes active. For the $19 \mathrm{~V} \beta$ genes we observed a similar result with $17.9 \pm 1.0$ genes utilized. An example Southern analysis is shown in Fig. $2 A$ and the densitometric readings in Fig. $3 A$. The degree of use of each individual family by the differing $\alpha$ and $\beta$ gene pools varied from 2.7 to $12.0 \%$ (mean \pm SEM $6.02 \pm 0.6$ ) of the total usage as gauged by the computerized densitometric assessments. These data are similar to those derived from quantitative PCR techniques involving the production of radiolabeled amplified products (7). The mean \pm 3 SDs for such observations gave an upper limit of a $13 \%$ contribution to the total $\mathrm{V}$ gene activity within an individual sample. In a previous report, we characterized the lack of effect of PHA on the expression of the hTcR V $\alpha$ gene repertoire and in the present experiments we again confirmed that PHA had little influence on $\mathrm{hTcR} V \beta$ gene expression (data not illustrated).

$h T c R V \alpha$ and $V \beta$ gene amplification in intrathyroidal $T$ cells. The mean utilization of the $18 \mathrm{~V} \alpha$ gene families in the six samples examined was $4.7(26 \%)$ but the mean utilization of the $19 \mathrm{~V} \beta$ gene families was $13.3(70 \%)(P<0.01)$ (Table $I$ and Figs. $2 B$ and $3 B$ ). The ranges of utilization were two to eight different $\mathrm{V} \alpha$ and eight to 18 different $\mathrm{V} \beta$ families. As reported previously (9), there were no consistent $\mathrm{V} \alpha$ gene families which failed to be expressed in this group of samples. However, using

Table I. Total hTcR V Gene Usage by Intrathyroidal T Cells

\begin{tabular}{cllcr}
\hline Sample & Disease & Source & $\# \mathrm{~V} \alpha^{*}$ & $\# \mathrm{~V} \beta$ \\
\hline p1 & Graves' & ITL & 6.0 & 8.0 \\
p2 & Graves' & ITL & 2.0 & 18.0 \\
p3 & Graves' & ITL & 2.0 & 11.0 \\
p4 & Hashimoto's & ITL & 6.0 & 15.0 \\
p5 & Graves' & ITL & 4.0 & 18.0 \\
p6 & Hashimoto's & ITL & 8.0 & 9.0 \\
Mean+SEM & & & $4.7 \pm 1.0$ & $13.3 \pm 1.9$ \\
& & & & \\
\hline
\end{tabular}

p, patient no. * Data (p1-4) for hTcR V $\alpha$ previously reported (9). 

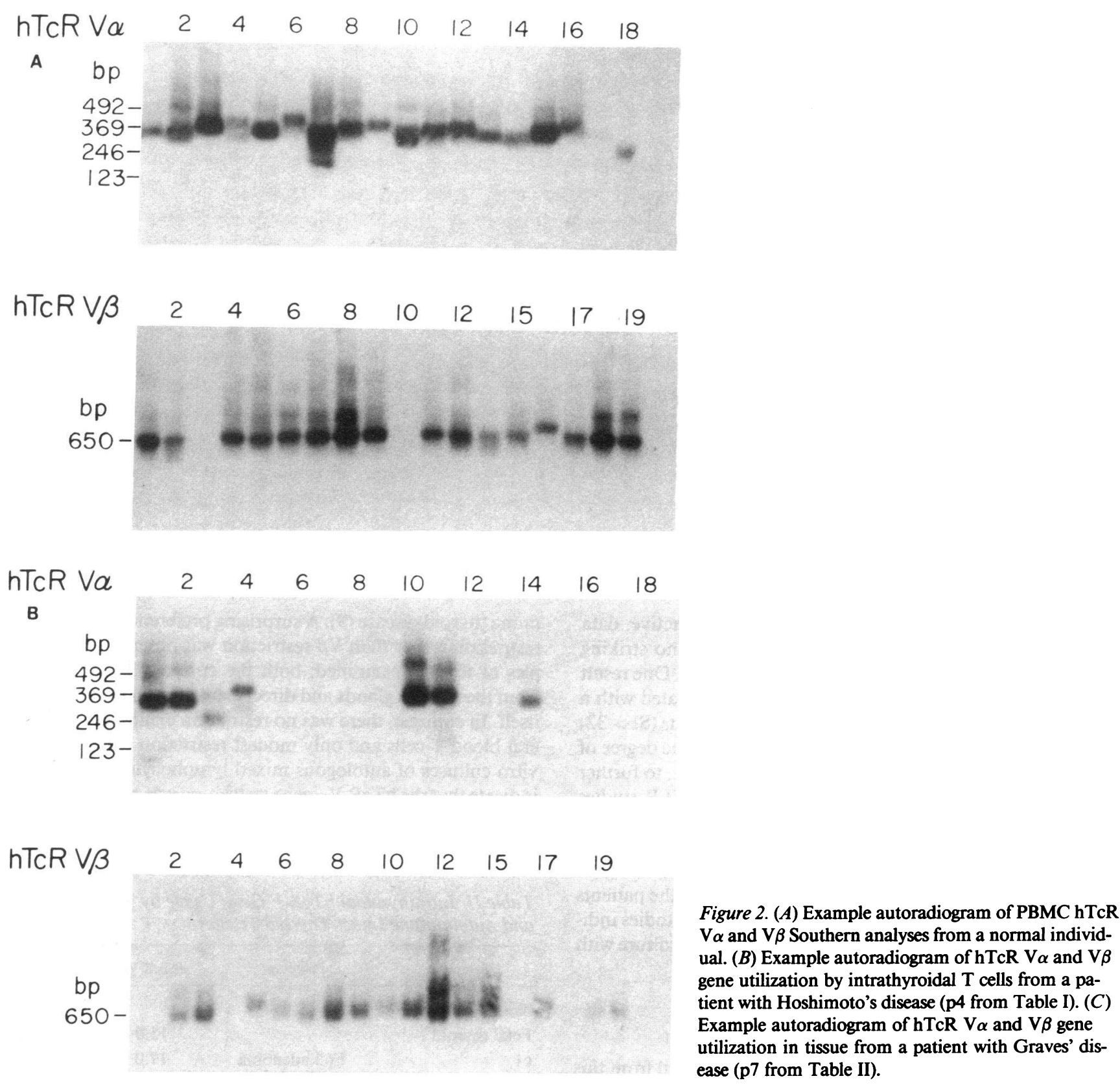

the criteria described above, with an upper limit of a $13 \%$ contribution, reexamination of our data indicated that certain $\mathrm{V} \alpha$ genes were excessively active in both the $T$ cell cultures and the intact thyroid tissue when compared to the peripheral circulation. For example, five of the six intrathyroidal $T$ cell samples analyzed demonstrated enhanced use of $\mathrm{hTcR}$ V $\alpha 1$.

$h T c R V$ gene utilization within intact thyroid tissue. Complementary DNA prepared from fetal human thyroid tissue cellular RNA demonstrated $15 \mathrm{~V} \alpha$ and $18 \mathrm{~V} \beta \mathrm{hTcR}$ gene families active and presumably reflective of the peripheral blood contamination of the tissue (data not illustrated). Eight samples of whole thyroid tissue cellular mRNA, obtained from seven benign follicular adenoma samples and one papillary carcinoma, similarly revealed full utilization of the $\mathrm{V} \alpha$ gene families with a mean \pm SEM of $16.6 \pm 0.5$ genes actively transcribing respectively (Table II). In contrast, cDNA samples from thyroid tissue retrieved from patients with autoimmune thyroid disease had showed a marked restriction in $\mathrm{V} \alpha$ gene usage but now we determined widespread $\mathrm{V} \beta$ gene utilization (means of $3.7 \pm 0.9$ and $15.7 \pm 0.7$, respectively) (Table II, Figs. 2 $C$ and $3 C$ ). When combined with the cultured intrathyroidal $\mathrm{T}$ cell hTcR V gene data it was also possible to now conclude that all samples showed preferential utilization of $\mathrm{V} \alpha 1,11$, or 12 .

Autologous mixed lymphocyte reactions (AMLRs) and $h T c R V$ gene usage. Six classical AMLRs were performed over $7 \mathrm{~d}$ on PBMC samples from unselected patients with autoimmune thyroid disease (two Graves' disease patients, four thyroiditis patients) (mean \pm SEM stimulation index 14.5 \pm 3.3 )(Table III). Examination of total cellular mRNA in these AMLRs revealed mild restriction with 3-13 V $\alpha$ gene families utilized (mean \pm SEM of $10.3 \pm 1.5, P<0.001$ compared to PBMC). Two 7-d AMLRs were examined from normal PBMC and pro- 

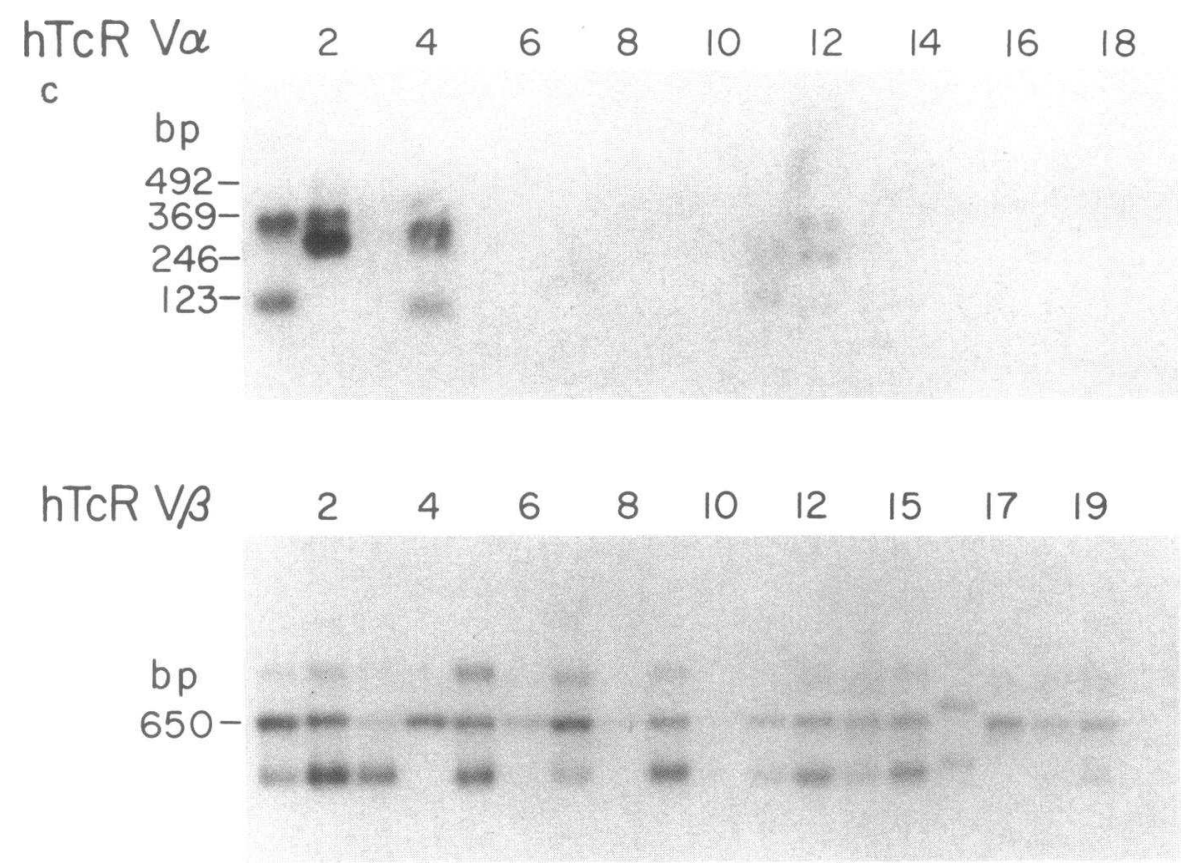

Figure 2 (Continued)

vided similar results (mean $14.5 \mathrm{hTcR} V \alpha$ genes active, data not illustrated). Within these samples there was no striking difference between the normal and patient AMLRs. One result with a marked restriction (AMLR p12) was associated with a significantly greater SI than all the other experiments (SI > 32) and raised the question of a relationship between the degree of stimulation and the degree of restriction. Therefore, to further confirm our interpretation, we also performed AMLR studies using a single target cell, rather than total non-T cells, with immortalized (via Epstein-Barr virus infection) autologous B cells as antigenic targets in similar AMLR studies. Experiments were performed with PBMC available from two of the patients with Graves' disease and one normal control. The studies indicated many active $h T c R$ V $\alpha$ and $V \beta$ genes after $7 \mathrm{~d}$ culture with no restriction at all (Table III).

\section{Discussion}

These data extend the observations recently reported from this laboratory concerning restricted usage of $\mathrm{hTcR} V \alpha$ genes by the intrathyroidal inflammatory cells of patients with autoim-
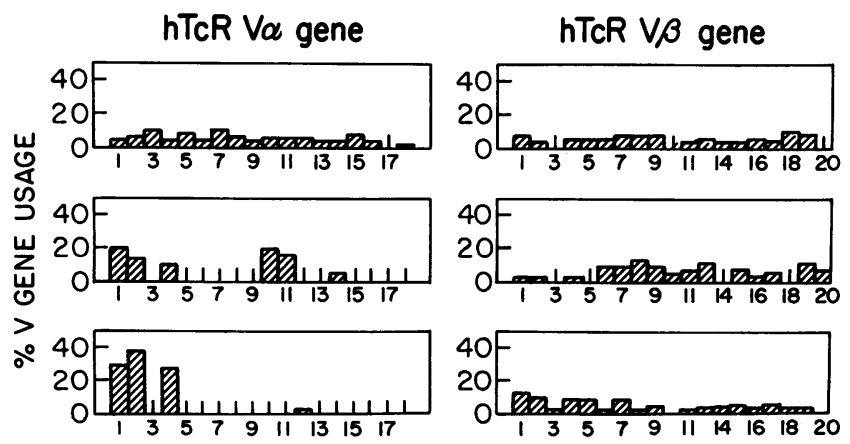

Figure 3. Diagrammatic representation of Figs. $2 A$ (top), $2 B$ (middle), and $2 C$ (bottom). Data were derived by computerized densitometry as described in Methods. mune thyroid disease (9). A surprising preference for $h T c R$ V $\alpha$ restriction rather than $\mathrm{V} \beta$ restriction was observed in all samples of thyroid examined; both the cultured $\mathrm{T}$ cells rescued from the thyroid glands and direct examination of intact tissue itself. In contrast, there was no restriction exhibited by peripheral blood $\mathrm{T}$ cells and only modest restriction exhibited by in vitro cultures of autologous mixed lymphocytes. Such results indicate that the $h T c R V \alpha$ gene restriction was not only secondary to HLA antigen autoreactivity but more likely to be associated with unique $\mathrm{T}$ cell-thyroid antigen interactions.

Table II. Intrathyroidal hTcR V Gene Usage by Nonautoimmune and Autoimmune Intact Thyroid Tissues

\begin{tabular}{llcc}
\hline \multicolumn{1}{c}{ Sample } & \multicolumn{1}{c}{ Pathology } & \#hTcR V $\boldsymbol{~}$ & \#hTcR V $\boldsymbol{r}$ \\
\hline Nonautoimmune & & & \\
Fetal thyroid & & 15.0 & - \\
c1 & Foll adenoma & 17.0 & - \\
c2 & MNG & 15.0 & - \\
c3 & MNG & 18.0 & - \\
c4 & MNG & 16.0 & - \\
c5 & Foll adenoma & 14.0 & - \\
c6 & Papillary Ca & 18.0 & - \\
c7 & MNG & 18.0 & - \\
c8 & Foll adenoma & 17.0 & - \\
Mean \pm SEM & & $16.6 \pm 0.5$ & \\
Autoimmune* & & & \\
p7 & & 3.0 & 17.0 \\
p8 & Graves' & 5.0 & 15.0 \\
p9 & Hashimoto's & 4.0 & - \\
p10 & Graves' & 3.0 & 15.0 \\
Mean \pm SEM & Hashimoto's & $3.7 \pm 0.9$ & $15.7 \pm 0.7$ \\
& & &
\end{tabular}

c, control; MNG, multinodular goiter. p, patient. * Data for hTcR V $\alpha$ previously reported (9). 
Table III. hTcR Va Gene Activity in cDNA Samples from AMLRs

\begin{tabular}{|c|c|c|c|c|c|c|}
\hline \multicolumn{7}{|c|}{ A. Classical AMLRs } \\
\hline Sample & Pathology & T only & T:non-T & SI & $\# \mathrm{~V} \alpha$ & $\# \mathrm{~V} \beta$ \\
\hline p11 & Graves' & $1,755 \pm 344$ & $9,461 \pm 1,223$ & 5.4 & 13 & - \\
\hline p12 & Hashimoto's & $846 \pm 262$ & $27,266 \pm 1,397$ & 32.2 & 3 & - \\
\hline p13 & Graves’ & $650 \pm 138$ & $8,217 \pm 566$ & 12.6 & 8 & - \\
\hline p14 & Hashimoto's & $1,983 \pm 645$ & $29,065 \pm 1,718$ & 14.6 & 13 & - \\
\hline p15 & Hashimoto's & $974 \pm 166$ & $10,655 \pm 2,716$ & 10.9 & 13 & - \\
\hline p16 & Hashimoto's & $895 \pm 341$ & $9,880 \pm 463$ & 11.0 & 12 & - \\
\hline Mean \pm SEM & & & & $14.5 \pm 3.3$ & $10.3 \pm 1.5$ & \\
\hline \multicolumn{7}{|c|}{ B. Nonclassical AMLRs } \\
\hline Sample & Pathology & PBMC & PBMC:EBV-3 & SI & $\# \mathrm{~V} \alpha$ & $\# \mathbf{V} \beta$ \\
\hline $\mathrm{n} 1$ & Normal & $15,505 \pm 1,010$ & $53,170 \pm 5,187$ & 3.4 & 17 & 17 \\
\hline pl & Graves' & $6,503 \pm 742$ & $24,489 \pm 2,507$ & 3.8 & 18 & 19 \\
\hline p3 & Graves' & $1,454 \pm 77$ & $8,520 \pm 267$ & 5.9 & 17 & 19 \\
\hline Mean \pm SEM & & & & $4.4 \pm 0.7$ & $17.3 \pm 0.6$ & $18.3 \pm 1.2$ \\
\hline
\end{tabular}

T cell data presented as mean \pm SEM cpm $\left[{ }^{3} \mathrm{H}\right]$-thymidine uptake. Background $<200 \mathrm{cpm}$ throughout $(A)$ and $<800 \mathrm{cpm}$ throughout $(B)$. SI, stimulation index. $\mathrm{n}$, normal; $\mathrm{p}$, patient. \#, no. of $\mathrm{V}$ genes active.

Examination of the T cell infiltrates of thyroid tissue from patients with autoimmune thyroid disease has shown a marked accumulation of a variety of $\mathrm{T}$ cell subsets including suppressor/cytotoxic (CD8+) and suppressor-inducer $(\mathrm{CD} 4+2 \mathrm{H} 4+) \mathrm{T}$ cell subsets in Graves' disease patients, whereas the more intense infiltrate of Hashimoto's disease has been more reflective of peripheral blood (1). Cloning of such $\mathrm{T}$ cells has shown examples of T cell reactivity to thyroglobulin (10), thyroid peroxidase (11), and intact thyroid cells $(10,12)$ but each appear to be present in low numbers within the thyroid infiltrate as judged by cloning frequency. However, such cloning studies have also demonstrated the difficulties in accumulating sufficient $T$ cells for detailed analysis because of the poor longevity of the human $T$ cell cultures. To date, hTcR V gene analysis of such clones has not been reported. We began our studies by analysis of the entire intrathyroidal $\mathrm{T}$ cell population rescued from thyroid tissue obtained at surgery $(1,9)$. Such studies demonstrated marked restriction of the $\mathrm{V} \alpha$ gene families utilized although the pattern of utilization varied from patient to patient. These data raised the possibility that the restriction in $\mathrm{hTcR} V$ gene usage was predicated by the thyroid antigenic targets within the intrathyroidal milieu. T cell lines and clones reactive to antigens such as myelin basic protein have been shown to exhibit hTcR V $\beta$ gene restriction $(8,17)$, whereas T cells examined in situ in plaques of patients with multiple sclerosis, who presumably have myelin basic protein-reactive T cells, demonstrated hTcR V $\alpha$ gene restriction (7). No reports to date, however, have examined hTcR V $\alpha$ and beta gene utilization in the same samples and this approach is clearly a useful step in understanding the antigen-driving of $h T c R ~ V$ gene utilization. Our earlier $h T c R$ V $\alpha$ studies led us to predict that $\mathrm{V} \beta$ restriction would also be present. However, using the same cDNA preparation for both $h T c R$ V $\alpha$ and $h T c R ~ V \beta$ analyses we found widespread $h T c R \quad V \beta$ gene utilization and this disparity requires explanation.
Because thyroid antigen-specific $\mathrm{T}$ cells are apparently infrequent within the thyroid, as judged by earlier cloning data $(10,12)$, we have previously suggested that the lymphocytic infiltrate within the thyroid gland may be secondary to "in vivo" AMLRs $(13,14)$. Such a phenomenon would help explain the large numbers of $T$ cells which appear not to be thyroid antigen reactive. The interpretation of the preferential hTcR V $\alpha$ but not $\beta$ gene usage within the thyroid was, therefore, investigated by the use of in vitro AMLRs. In these studies there was only a modest restriction of $h T c R ~ V \alpha$ gene utilization, a phenomenon quite distinct to the intrathyroidal $\mathrm{T}$ cell data that showed strong restriction. Because AMLRs are thought to be primarily MHC antigen driven (18), these observations suggested that the intrathyroidal $T$ cell data were secondary to a distinct physiological process. However, our conclusions must be tentative because of the short-term nature of the AMLR data which may not have allowed enough time for restriction to occur and because in at least one experiment with a high stimulation index we found an associated $\mathrm{V}$ gene restriction.

One likely explanation for $\mathrm{hTcR}$ V $\alpha$ gene restriction was a thyroid-antigen driven reaction to select those specific $h T c R$ $\mathrm{V} \alpha$ genes which allowed successful thyroid antigen presentation to the patient's $T$ helper cells. Earlier reports from this laboratory demonstrated that in vitro mixed cell reactions between thyroid cells, induced to express MHC class II antigens, and autologous PBMC were interpreted by us as evidence of in vivo AMLR reactions within the thyroid glands of patients with autoimmune thyroid disease $(19,20)$. However, data have also suggested that such mixed cell reactivity represented specific recognition of thyroid antigens in association with $\mathrm{MHC}$ class II antigens (21). The present $\mathrm{hTcR} V$ gene analyses would suggest that the in vitro AMLR may not be the same as the thyroid cell/ $\mathrm{T}$ cell reaction in vivo. Our recent demonstration that rat thyroid epithelial cells have the capacity for thyroid 
antigen presentation, even in the absence of any other potential antigen presenting cells (15), is further evidence for the potentially unique nature of the thyroid cell/T cell interaction in autoimmune thyroid disease.

Another possible explanation for the data generated by these $\mathrm{V}$ gene studies would be the presence of an intrathyroidal antigen capable of activating $T$ lymphocytes on the basis of their $h T c R$ V $\alpha$ chain usage. The concept of a superantigen acting as a mitogen to stimulate a variety of nonantigen specific $T$ cells from a restricted group of $T$ cells utilizing particular $V$ genes has been well documented (22). Typically, superantigenic mitogens have acted via $h T c R \mathrm{~V} \beta$ genes rather than $\mathrm{V} \alpha$ genes (23) but there seem to be no strong experimental data to indicate why a "superantigen" could not act via the hTcR V $\alpha$ gene. Because the vast majority of $T$ cells which make up a lymphocytic infiltrate in tissue from patients with autoimmune thyroid disease are of unknown specificity (13) it would appear unlikely that the hTcR V genes utilized on examination of the total thyroid cellular RNA represent activity from thyroid antigen-specific $T$ cells. Hence, another mechanism, or mechanisms, needs to be considered for their activation. Because it appears that an AMLR-like process may be less likely, the possibility of a "superantigen" being present should be carefully considered. Such a concept is open to experimental investigation in a variety of disease states.

\section{Acknowledgments}

We thank Dr. A. E. Schwartz and E. A. Friedman for access to surgical material.

This work was supported in part by grants DK28243 and DK35764 from the National Institute of Diabetes, Digestive and Kidney Diseases (to T. F. Davies), and the Charles H. Revson Foundation (to A. Martin), and by the Cancer Research Institute/Albert and Cherry Krassner Investigator Award (to A. Ben-Nun). T. F. Davies is the Florence \& Theodore Baumritter Professor of Medicine, A. Ben-Nun is the incumbent of the Swig-Weiler Career Development Chair.

\section{References}

1. Martin, A., N. K. Goldsmith, E. W. Friedman, A. E. Schwartz, T. F. Davies, and S. H. Roman. 1990. Intrathyroidal accumulation of T cell phenotypes in autoimmune thyroid disease. Autoimmunity. 6:269-281.

2. Maron, R., R. Zerubavel, A. Friedman, and I. R. Cohen. 1983. T lymphocyte line specific for thyroglobulin produces or vaccinates against autoimmune thyroiditis in mice. J. Immunol. 131:2316-2322.

3. Romball, C. G., and W. O. Weigle. 1987. Transfer of experimental autoimmune thyroiditis with T cell clones. J. Immunol. 138:1092-1098.

4. Ben-Nun, A., H. Wekerle, and I. R. Cohen. 1981. The rapid isolation of clonable antigen-specific $\mathrm{T}$ lymphocytes capable of mediating autoimmune encephalitis. Eur. J. Immunol. 11:195-199.

5. Pette, M., K. Fujita, D. Wilkinson, D. M. Altmann, J. Trowsdale, G. Giegerich, A. Hinkkanen, J. T. Epplen, L. Kappos, and H. Wekerle. 1990. Myelin autoreactivity in multiple sclerosis: recognition of myelin basic protein in the content of HLA-OR2 products of T lymphocytes of multiple-sclerosis patients and healthy donors. Proc. Natl. Acad. Sci. USA. 87:7968-7972.

6. Burns, F. R., L. Xiaobin, N. Shen, H. Offner, Y. K. Chou, A. A. Vandenbark, and E. Heber-Katz. 1989. Both rat and mouse T cell receptors specific for the encephalitogenic determinant of MBP use similar $\mathrm{V} \alpha$ and $\mathrm{V} \beta$ chain genes even though the major encephalitogenic determinants being recognized are different. J. Exp. Med. 169:27-39.

7. Oksenberg, J. R., S. Stuart, A. B. Begovich, R. B. Bell, H. A. Erlich, L Steinman, and C. A. Bernard. 1990. Limited heterogeneity of rearranged T cell receptor $\mathrm{V}$ alpha transcripts in brains of multiple sclerosis patients. Nature (Lond.). 345:344-346.

8. Ben-Nun, A., R. S. Liblau, L. Cohen, D. Lehmann, E. Tournier-Lasseru, A. Rosenzwig, Z. Jingwu, C. M. Raus, and M. A. Bach. 1991. Restricted T cell receptor $\mathrm{V}$ beta usage by myelin basic protein-specific $\mathrm{T}$ cell clones in multiple sclerosis: predominant genes vary in individuals. Proc. Natl. Acad. Sci. USA. 88:2466-2470.

9. Davies, T. F., A. Martin, E. S. Concepcion, P. Graves, L. Cohen, and A. Ben-Nun. 1991. T cell receptor $\mathrm{V}$ alpha gene usage in autoimmune thyroid disease: marked restriction in heterogeneity of intrathyroidal T cells. $N$. Engl. $J$. Med. 325:238-244.

10. Mackenzie, W. A., A. E. Schwartz, E. W. Friedman, and T. F. Davies 1987. Intrathyroidal $T$ cell clones from patients with autoimmune thyroid disease. J. Clin. Endocrinol. Metab. 64:818-824.

11. Fisfalen, M. E., L. J. DeGroot, J. Quintans, W. A. Franklin, and K Soltani. 1988. Microsomal antigen-reactive lymphocyte lines and clones derived from thyroid tissue of patients with Graves' disease. J. Clin. Endocrinol. Metab. 66:776-784.

12. Londei, M., G. F. Bottazzo, and M. Feldman. 1985. Human T cell clones from autoimmune glands: specific recognition of autologous thyroid cells. Science (Wash. DC). 228:85-88.

13. Piccinini, L. A., S. H. Roman, and T. F. Davies. 1987. Autoimmune thyroid disease and thyroid cell class II major histocompatibility complex antigens. Clin. Endocrinol. 26:253-272.

14. Davies, T. F., A. Martin, and P. Graves. 1988. Human autoimmune thyroid disease: cellular and molecular aspects. Baillière's Clinical Endocrinology and Metabolism. 2:911-939.

15. Kimura, H., and T. F. Davies. 1991. Thyroid specific T cells in the normal Wistar rat. II. T cell clones interact with cloned Wistar rat thyroid cells and provide direct evidence for autoantigen presentation by thyroid epithelial cells. Clin. Immunol. Immunopathol. 58:195-206.

16. Davies, T. F., and M. Platzer. 1986. The T cell suppressor defect in autoimmune thyroiditis: evidence for a high set 'autoimmunostat'. Clin. Exp. Immunol. 63:73-79.

17. Wucherpfennig, K. W., K. Ota, N. Endo, J. G. Seidman, A. Rosenzweig, H. L. Weiner, and D. A. Hafler. 1990. Shared human T cell receptor V beta usage to immunodominant regions of myelin basic protein. Science (Wash. DC). 248:1016-1020.

18. Lechler, R. I., G. Lombardi, J. R. Batchelor, N. Reinsmoen, and F. H Bach. 1990. The molecular basis of alloreactivity. Immunol. Today. 11:83-89.

19. Davies, T. F. 1985. Co-cultures of human thyroid monolayer cells and autologous T cells: impact of HLA class II antigen expression. J. Clin. Endocrinol. Metab. 61:418-422.

20. Hirose, W., N. Lahat, M. Platzer, S. Schmitt, and T. F. Davies. 1988 Activation of MHC-restricted rat T cells by cloned syngeneic thyrocytes. $\mathrm{J}$. Immunol. 141:1098-1102.

21. Lahat, N., M. Sheinfeld, E. Baron, and Z. Kraim. 1991. Class II HLA-DR antigens on non-autoimmune human thyroid cells stimulate autologous $T$ cells with high suppressor activity. Autoimmunity. 4:125-133.

22. Choi, Y., B. L. Kotzin, L. Herron, J. Callahan, P. Marrack, and J. Kappler. 1989. Interaction of $S$. aureus toxin superantigens with human $T$ cells. Proc. Natl. Acad. Sci. USA. 86:8941-8955.

23. White, J., A. Herman, A. M. Pullen, R. Kube, J. W. Kappler, and P. Marrack. 1989. The V $\beta$-specific superantigen Staphylococcal enterotoxin B. Stimulation of mature $\mathrm{T}$ cells and clonal deletion in neonatal mice. Cell. 56:27-35. 